\title{
Effectiveness of online cognitive behavioral therapy on family caregivers of people with dementia
}

\author{
Timothy Kwok ${ }^{1,2}$ \\ Alma $\mathrm{Au}^{3}$ \\ Bel Wong' \\ Isaac IP' \\ Vivian Mak' \\ Florence Ho' \\ 'Jockey Club Centre for Positive \\ Ageing, ${ }^{2}$ Department of Medicine and \\ Therapeutics, Chinese University \\ of Hong Kong; ${ }^{3}$ Department of \\ Applied Social Sciences, Hong Kong \\ Polytechnic University, Hong Kong
}

\author{
This article was published in the following Dove Press journal: \\ Clinical Interventions in Aging \\ I I April 2014 \\ Number of times this article has been viewed
}

Purpose: Family caregivers of persons with dementia (PWD) may receive caregiver training because of logistical constraints and privacy concerns. This study evaluated the effectiveness of an online intervention for family caregivers of PWD in improving their self-efficacy in managing behavioral and psychological symptoms of dementia (BPSD), and their emotion well-being.

Subjects and methods: A total of 36 family caregivers of people with dementia participated in a 9-week online intervention based on the cognitive behavioral therapy model. Outcomes of the intervention were measured by the Chinese version of the Neuropsychiatric Inventory Questionnaire and two domains of the Revised Scale for Caregiving Self-Efficacy. Wilcoxon signed rank tests were used to compare the change in outcome variables.

Results: The severity of BPSD of PWD and BPSD-related distress in family caregivers showed a statistically significant reduction after the intervention. Subgroup analysis showed self-efficacy in controlling upsetting thoughts significantly improved in caregivers of PWD at moderate to severe stages.

Conclusion: Online cognitive behavioral therapy for family caregivers reduced BPSD of PWD and the related distress in their caregivers.

Keywords: online intervention, dementia caregiver, emotional self-efficacy, BPSD

\section{Introduction}

Dementia is a degenerative condition that not only affects the patients but also, their family caregivers. Caregiving burden adversely affects the physical, emotional, and psychological well-being of the caregivers, ${ }^{1-4}$ greatly impairing the caregivers' ability to care and causing health problems for the caregivers. Caregiving skill training, when combined with counseling, can improve emotional well-being, social support, and skills for handling of behavioral and psychological symptoms of dementia (BPSD) and can reduce the time of direct care $^{5-8}$ and enhance the physical and psychological health of caregivers. ${ }^{9}$

Training programs for family caregivers of persons with dementia (PWD) are usually delivered face-to-face. Thus, family caregivers who are at work or heavily engaged in caring tasks may not be able to participate. Moreover, some family caregivers may have privacy concerns. Internet-based interventions, which the caregivers could receive at home, may be a viable alternative. In the past decades, computer ownership within Hong Kong households has been rising, with an annual rate of 5.2\%, and home-use Internet connection has risen by $7.8 \%$ per annum. According to the census statistics in 2012 , over $90 \%$ of Hong Kong residents aged between 25 and 44 years have used the Internet, and the majority of Hong Kong residents aged 10 years or above spent
Correspondence: Bel Wong Jockey Club Centre for Positive Ageing, 27 A Kung Kok Street, Shatin, NT, Hong Kong

Tel +852 26326323

Fax +852 26360323

Email research@jccpahk.com 
10 to 30 hours per week surfing the Internet. ${ }^{10}$ There have been studies showing that interventions offered through computer or Internet may help improve anxiety and depression, which are prevalent among family caregivers of PWD. ${ }^{11-13}$ There are websites that provide information on dementia care for caregivers, but few provide information on the maintenance of psychological health of caregivers. Moreover, online counseling for family caregivers of PWD is rare.

To fill this service gap, we designed a website with an online counseling component for family caregivers of PWD in Hong Kong. The website, ADCarer.com, was inspired by an e-learning program for family caregivers of PWD in the Netherlands. ${ }^{14}$ The content was guided by a study ${ }^{15}$ that revealed that the pressing concerns of caregivers of PWD were activity arrangement, handling of BPSD, such as combativeness and confusion, and communication with care recipient; in addition, healthy lifestyle, grief, and relaxation also concerned the caregivers. These findings helped to form the skeleton of ADCarer.com. The website offers selflearning for basic training on caring skills, illustrated by multimedia presentations. It also contains training on stress reduction, grief handling, and healthy lifestyle maintenance, to help caregivers develop effective psychological coping strategies and master stress-reduction skills to manage their caring burden. Such psychoeducation has been shown to be effective in reducing depressive symptoms of family caregivers of PWD. ${ }^{16,17}$

In addition, the website offers individualized online counseling support to family caregivers, using cognitive behavioral therapy (CBT) as the theoretical framework. CBT has been shown to be effective in anxiety reduction in caregivers of PWD. ${ }^{18-20}$ It is hypothesized that anxiety due to caregiving may induce maladaptive beliefs in caregivers of PWD, which can hinder them from exploring and implementing pragmatic caregiving, and which can cause distress to them. CBT may help to modify the maladaptive anxiety so that caregivers may be motivated to adopt a more positive attitude toward their caregiving tasks. In CBT interventions, caregivers are required to record behaviors and thoughts. Designated trained counselors are assigned to provide feedback on the behavioral and thought logs and on issues that the caregivers are concerned about.

The present study investigated the effectiveness of the online CBT intervention in improving the self-efficacy of family caregivers of PWD. It was hypothesized that the online intervention could help caregivers of PWD to handle BPSD and improve their self-perceived competence in dementia care.

\section{Methods}

The study adopted a within-subjects pretest-posttest design. Email invitation was sent to family caregivers of users of a dementia day care center and memory clinic at the Hong Kong Jockey Club Centre for Positive Ageing (a comprehensive care center for PWD), and promotion was also done online via the center website. A total of 36 family caregivers of dementia patients were recruited between January and August 2012. The participants were initially interviewed in person by a social worker, in order to screen for their eligibility for the study. Participants were included in the program if: their care recipients had a clinical diagnosis of dementia; they were the primary caregivers of the care recipients; and they had no major depression. Written consent was obtained for all subjects, and ethics approval was obtained from the Survey and Behavioural Research Ethics Committee of the Chinese University of Hong Kong.

The intervention lasted for 9 weeks. The designated counselors were clinical psychologists, social workers, or counselors who had training and practice in CBT. In the first week of the intervention, after establishing rapport, the subjects were asked to identify their two most disturbing BPSDs. For the subsequent 8 weeks, the counselor went through each BPSD with the subject, and sought solutions together. In total, it took 8 weeks to address the two major BPSDs. In the CBT intervention protocol, the participants were asked to record the antecedent, behavior, and consequence, on an online worksheet, every time the care recipient displayed the BPSD. CBT coined the "cognitive model", which pointed out how the situation triggering psychological disturbance, the thoughts, and the reaction to the situation inter-related (situation $\rightarrow$ automatic thoughts/intermediate thoughts/core beliefs $\rightarrow$ reaction), ${ }^{21}$ while CBT focused its intervention on the thoughts and beliefs. The intervention of this study thus was based on information in the worksheet and attempted to help the participants understand their cognitive model towards the caring difficulties and to identify and modify any maladaptive beliefs so that they could be motivated to explore more adaptive solutions and implement more effective management skills and solutions. The intervention was based on back-and-forth online messaging between the counselor and individual subjects. The counselors responded to the messages of the participants within 48 hours. There was no upper limit to the total number of messages, but subjects were requested to provide at least one record per week. The last week of the intervention was for review.

In addition to the aforementioned CBT intervention, the participants were also asked to record the number, content, 
and pattern of their own self-care behaviors. The intervener tracked the records and discussed emotion management with the caregivers, helping them build good self-care habits as a supplement to the CBT intervention. The subjects were encouraged to go through the psychoeducation part of the website themselves. To assist learning, key messages were summarized by seven multimedia PowerPoint 2007 (Microsoft Corporation, Redmond, WA, USA) presentations. The topics include BPSD and techniques to validate the needs and values of the care recipients, behavior management and the person-centered care model, positive psychology and caregiving, meditation, mindful breathing, cognitive restructuring, and self-recognition. The framework of the

Table I Intervention protocol

\begin{tabular}{|c|c|c|}
\hline Week & Intervention contents & $\begin{array}{l}\text { Supporting } \\
\text { materials }\end{array}$ \\
\hline I & $\begin{array}{l}\text { Rapport building } \\
\text { Therapeutic goal setting } \\
\text { Identification of BPSD, number I } \\
\text { Delivery of homework }\end{array}$ & NA \\
\hline 2 & $\begin{array}{l}\text { Review of homework } \\
\text { Exploration, response, and } \\
\text { discussion of maladaptive thoughts } \\
\text { regarding BPSD, number I }\end{array}$ & $\begin{array}{l}\text { BPSD and validation } \\
\text { techniques }\end{array}$ \\
\hline 3 & $\begin{array}{l}\text { Review of homework } \\
\text { Modification of maladaptive } \\
\text { thoughts regarding BPSD, number I }\end{array}$ & $\begin{array}{l}\text { Cognitive } \\
\text { restructuring }\end{array}$ \\
\hline 4 & $\begin{array}{l}\text { Review of homework } \\
\text { Emphasizing positive outcomes } \\
\text { Exploration of effective and } \\
\text { practical coping strategies for } \\
\text { BPSD, number I } \\
\text { Discussion on self-help strategies }\end{array}$ & $\begin{array}{l}\text { Behavior } \\
\text { management and } \\
\text { PCC model }\end{array}$ \\
\hline 5 & $\begin{array}{l}\text { Review of homework } \\
\text { Exploration, response, and discussion } \\
\text { on maladaptive thoughts } \\
\text { regarding BPSD, number } 2\end{array}$ & $\begin{array}{l}\text { Positive psychology } \\
\text { and caregiving }\end{array}$ \\
\hline 6 & $\begin{array}{l}\text { Review of homework } \\
\text { Modification of maladaptive } \\
\text { thoughts regarding BPSD, number } 2\end{array}$ & Meditation \\
\hline 7 & $\begin{array}{l}\text { Review of homework } \\
\text { Emphasizing positive outcomes } \\
\text { Exploration of effective and } \\
\text { practical coping strategies for } \\
\text { BPSD, number } 2 \\
\text { Discussion on self-help strategies }\end{array}$ & Mindful breathing \\
\hline 8 & $\begin{array}{l}\text { Consolidation of intervention } \\
\text { outcomes } \\
\text { Consolidation on self-help strategies }\end{array}$ & Self-recognition \\
\hline 9 & $\begin{array}{l}\text { Review of intervention } \\
\text { Intervention termination }\end{array}$ & NA \\
\hline
\end{tabular}

Note: The order of delivery of supporting materials may vary according to the needs of participants.

Abbreviations: BPSD, behavioral and psychological symptoms of dementia; NA, not applicable; PCC, person-centered care. intervention is listed in Table 1. All services were provided free of charge.

Demographic information on the caregivers and the care recipients, and staging of dementia were collected at the baseline visit. The outcome measures were self-administered online by the family caregivers before and 1 month after the CBT intervention. They were as follows: BPSD management and related self-efficacy was measured by the Chinese version of the Neuropsychiatric Inventory Questionnaire (NPI-Q). ${ }^{22,23}$ The questionnaire consisted of 12 BPSD domains (delusions, hallucinations, agitation, depression or dysphoria, anxiety, elation, apathy, disinhibition, irritability, motor disturbance, nighttime behaviors, and appetite). Caregivers indicated the severity of the 12 symptoms ( $1=$ mild, $2=$ moderate, $3=$ severe; and 0 , if a BPSD was absent) and their level of distress $(0=$ not at all, $1=$ minimally, $2=$ mildly, $3=$ moderately, $4=$ severely, and 5= extremely) in response to each particular BPSD respectively. Total severity and distress scores were yielded by summing the corresponding scores across the 12 items. Caregiving self-efficacy was measured by the Chinese version of the Revised Scale for Caregiving Self-Efficacy (RSCSE). ${ }^{24,25}$ With regard to the research hypotheses, two domains of the scale, namely, responding to disturbing behaviors (CSE-RDB) (five items) and controlling upsetting thoughts (CSE-CUT) (five items) were selected for measurement. Caregivers rated their level of confidence in executing specific caregiving-related tasks on a scale $(0 \%$ to $100 \%$ ) according to their recent situation. Percentage scores in each subscale (ie, domain) were averaged to yield a domain score. Cronbach's alpha for the CSE-RDB and CSE-CUT were 0.95 and 0.91 , respectively, for the pretest and 0.93 and 0.85 , respectively, for the posttest.

\section{Data analysis}

Statistical analyses were performed with SPSS software version 20 (IBM Corp, Armonk, NY, USA). Descriptive statistics of demographic and outcome variables were first calculated. Characteristics of the caregivers who completed the study were compared against those who dropped out of the study using chi-square tests (categorical data) and independent samples $t$ tests or Mann-Whitney $U$ tests (continuous data) to reveal any systematic differences between completers and noncompleters. Changes in outcome variables (caregiving self-efficacy, BPSD, caregiver distress) were tested by comparing pretest and posttest data using paired $t$ tests and Wilcoxon signed rank tests. Subgroup analysis was done across selected demographic variables; only the results with statistical significance are presented. 


\section{Results}

In all, 36 participants were recruited, and ten of them dropped out of the study. The reasons for drop out included the following: death of care recipient $(n=3)$, participants not available for posttest $(\mathrm{n}=6)$, and drop out of participant $(n=1)$. The demographic and baseline characteristics of the recruited participants (completers versus noncompleters) are listed in Table 2. Analysis of the baseline characteristics of the completers against the noncompleters indicated that the two groups were comparable on all variables.

\section{BPSD severity and caregiver distress}

Comparison between pretest and posttest scores on BPSD severity and caregiver distress are shown in Table 3. After the online intervention, the total severity score showed a statistically significant reduction from pretest (mean $[\mathrm{M}]=11.9$, standard deviation $[\mathrm{SD}]=6.37)$ to posttest $(\mathrm{M}=7.46$,

Table 2 Demographic variables of recruited participants $(N=36)$

\begin{tabular}{|c|c|c|c|}
\hline & \multicolumn{2}{|l|}{$\mathbf{N}(\%) / M(S D)$} & \multirow[t]{2}{*}{$P$} \\
\hline & $\begin{array}{l}\text { Completers } \\
(n=26)\end{array}$ & $\begin{array}{l}\text { Noncompleters } \\
(n=10)\end{array}$ & \\
\hline Caregiver sex & & & 0.85 \\
\hline Female & 19 (73.1\%) & 7 (70.0\%) & \\
\hline Male & 7 (26.9\%) & $3(30.0 \%)$ & \\
\hline Caregiver age range, years & & & 0.774 \\
\hline $31-40$ & $2(7.7 \%)$ & $0(0 \%)$ & \\
\hline $4 I-50$ & $10(38.5 \%)$ & $5(50.0 \%)$ & \\
\hline $5 I-60$ & $12(46.2 \%)$ & $5(50.0 \%)$ & \\
\hline$>60$ & $2(7.7 \%)$ & $0(0 \%)$ & \\
\hline Caregiver education level & & & 0.443 \\
\hline Secondary/diploma & $15(57.7 \%)$ & $7(70.0 \%)$ & \\
\hline Graduate & $6(23.1 \%)$ & $2(20.0 \%)$ & \\
\hline Postgraduate & 5 (19.2\%) & I (I0.0\%) & \\
\hline Relationship with patient & & & 0.371 \\
\hline Spouse & 5 (19.2\%) & I (I0.0\%) & \\
\hline Children & $16(61.5 \%)$ & $9(90.0 \%)$ & \\
\hline Children-in-law & $3(11.5 \%)$ & $0(0 \%)$ & \\
\hline Grandchildren & $2(7.7 \%)$ & $0(0 \%)$ & \\
\hline Patient sex & & & 0.293 \\
\hline Female & $16(61.5 \%)$ & $8(80.0 \%)$ & \\
\hline Male & 10 (38.5\%) & $2(20.0 \%)$ & \\
\hline Patient age, years & $80.4(7.94)$ & $83.4(9.92)$ & 0.288 \\
\hline Stage of dementia* & & & 0.641 \\
\hline Mild & I5 (57.7\%) & $5(50.0 \%)$ & \\
\hline Moderate to severe & $10(38.5 \%)$ & $3(30.0 \%)$ & \\
\hline Unsure & $\mathrm{I}(3.8 \%)$ & $2(20.0 \%)$ & \\
\hline BPSD severity $(\max 36)$ & $11.9(6.37)$ & II.5 (4.93) & 0.821 \\
\hline Caregiver distress $(\max 36)$ & $15.6(10.9)$ & I $4.3(7.45)$ & 1.00 \\
\hline CSE-RDB $(\max 100)$ & $56.1(20.6)$ & $63.0(23.9)$ & 0.590 \\
\hline CSE-CUT $(\max 100)$ & $54.2(22.2)$ & $65.9(22.7)$ & $0.24 I$ \\
\hline
\end{tabular}

Note: *as reported by the caregiver.

Abbreviations: BPSD, behavioral and psychological symptoms of dementia; CSECUT, caregiving self-efficacy - controlling upsetting behaviors*; CSE-RDB, caregiving self-efficacy - responding to disruptive behaviors; M, mean; SD, standard deviation.
Table 3 Intervention outcome measures

\begin{tabular}{llll}
\hline Outcome measures & \multicolumn{1}{l}{$\mathbf{M}(\mathbf{S D})$} & $\boldsymbol{P}$ \\
\cline { 2 - 3 } & Pretest & Posttest & \\
\hline BPSD severity & $\mathrm{II} .9(6.37)$ & $7.46(6.07)$ & 0.003 \\
Caregiver distress & $15.6(10.9)$ & $10.7(10.1)$ & 0.012 \\
CSE-RDB & $56.1(20.6)$ & $62.2(16.1)$ & 0.228 \\
CSE-CUT & $54.2(22.2)$ & $62.4(15.3)$ & 0.122 \\
\hline
\end{tabular}

Note: *as reported by the caregiver.

Abbreviations: BPSD, behavioral and psychological symptoms of dementia; CSE-CUT, caregiving self-efficacy - controlling upsetting behaviors*; CSE-RDB, caregiving self-efficacy - responding to disruptive behaviors; M, mean; SD, standard deviation.

$\mathrm{SD}=6.07), Z=3.02, P<0.01, r=0.59$. Similarly, caregiver distress score decreased from pretest $(\mathrm{M}=15.6, \mathrm{SD}=10.9)$ to posttest $(\mathrm{M}=10.7, \mathrm{SD}=10.1)$, resulting in a statistically significant reduction, $Z=2.51, P<0.05, r=0.49$. There was no significant result from the subgroup analysis.

\section{Caregiving self-efficacy}

The pretest and posttest scores on CSE-RDB and CSE-CUT are listed in Table 3. Caregivers reported higher CSE-CUT scores at posttest $(M=62.4, S D=15.3)$ than at pretest $(M=54.2$, $\mathrm{SD}=22.2)$, as well as higher CSE-RDB scores at posttest ( $\mathrm{M}=62.2, \mathrm{SD}=16.1)$ than at pretest $(\mathrm{M}=56.1, \mathrm{SD}=20.6$ ), although this increase was not significant $(Z=1.55, P=0.122$ [CSE-CUT]; $Z=1.21, P=0.228$ [CSE-RDB]). Subgroup analysis showed that participants taking care of people with severe dementia had a significant increase in CSE-CUT score after the intervention $(Z=2.33, P<0.05)$ (Table 4).
0.443

$0.37 \mid$

0.293

0.288

0.641

.821

1.00

0.590

0.241

西

Note: *as reported by the caregiver.
Abbreviations: BPSD, behavioral and psychological symptoms of dementia; CSE-
CUT, caregiving self-efficacy - controlling upsetting behaviors*; CSE-RDB, caregiving
self-efficacy - responding to disruptive behaviors; M, mean; SD, standard deviation; $U$, Mann-Whitney $U$ value. 
with studies of CBT in relieving caregiving anxiety and distress. ${ }^{28,29}$

As computer literacy and access to the Internet were required, the subjects were biased toward those younger caregivers with a higher level of education. Among the caregivers who agreed to join, most completed the 9-week program. There was no significant difference between the completers and noncompleters in baseline characteristics. This suggests that online intervention is a feasible alternative for the computer literate family caregivers of PWD.

The primary objective of the intervention was to reduce the family caregivers' distress from BPSD. It was interesting to observe a significant reduction in the perceived BPSD in the older family members with dementia as well. This is consistent with the notion that at least part of the BPSD is caused by communication problems between caregivers and the care recipients. ${ }^{30}$

An important objective of the intervention was to increase the self-efficacy of the family caregivers. It was somewhat disappointing that this CBT program did not appear to improve self-efficacy, despite a significant reduction in BPSD. A possible explanation is that it takes time and experience for self-efficacy to be established. A longer online CBT program, of 16 weeks, was shown to be effective in improving self-efficacy in family caregivers of PWD. ${ }^{31}$ One caregiver intervention study found that improvement in self-efficacy was not initially significant at posttest but was significant at the 3-month follow-up; ${ }^{32}$ further research, with randomized design to compare different intervention lengths, was suggested so as to find an optimal intervention mode that would be best accepted by community-dwelling caregivers.

On the other hand, the subgroup analysis suggested that family caregivers of people with moderate to severe dementia did improve their self-efficacy in controlling upsetting thoughts, though not in managing BPSD. The emotional support and self-care component in this intervention might have been better suited to the needs of caregivers of people with more severe dementia, prompting them to review their caring experiences and search for inner gain in their caring work..$^{33}$ It may take longer for CBT to improve self-efficacy in managing BPSD as BPSD varies with time, both in its nature and severity.

The limitations of this study were the small sample size and the absence of a control group. Because we wanted to allow the participants to complete the assessment online, we did not measure other potentially important outcomes eg, perceived caregiver burden and mood.
We concluded that CBT intervention delivered online is feasible in family caregivers of PWD, that it was effective in reducing the caregiver distress due to BPSD, and that it may even reduce the severity of BPSD as well. Nine weeks may not be sufficient for CBT to improve self-efficacy in dementia care - a longer period of online support is recommended. Based on our encouraging results, a randomized controlled trial of online CBT to reduce psychological symptoms and caregiver burden is warranted.

\section{Disclosure}

The authors report no conflicts of interest in this work.

\section{References}

1. Mausbach BT, Patterson TL, Rabinowitz YG, Grant I, Schulz R. Depression and distress predict time to cardiovascular disease in dementia caregivers. Health Psychol. 2007;26(5):539-544.

2. Schubert CC, Boustani M, Callahan CM, Perkins AJ, Hui S, Hendrie HC Acute care utilization by dementia caregivers within urban primary care practices. J Gen Intern Med. 2008;23(11):1736-1740.

3. Schulz R, Beach SR. Caregiving as a risk factor for mortality: the Caregiver Health Effects Study. JAMA. 1999;282(23):2215-2219.

4. Schulz R, Martire LM. Family caregiving of persons with dementia: prevalence, health effects, and support strategies. Am J Geriatr Psychiatry. 2004;12(3):240-249.

5. Brodaty H, Green A, Koschera A. Meta-analysis of psychosocial interventions for caregivers of people with dementia. J Am Geriatr Soc. 2003;51(5):657-664.

6. Nichols LO, Martindale-Adams J, Greene WA, Burns R, Graney MJ, Lummus A. Dementia caregivers' most pressing concerns. Clin Gerontol. 2008;32(1):1-14.

7. Pinquart M, Sörensen S. Helping caregivers of persons with dementia: which interventions work and how large are their effects? Int Psychogeriatr. 2006;18(4):577-595.

8. Zarit S, Femia E. Behavioral and psychosocial interventions for family caregivers. J Soc Work Educ. 2008;44(Suppl 3):S49-S57.

9. Burns R, Nichols LO, Martindale-Adams J, Graney MJ, Lummus A. Primary care interventions for dementia caregivers: 2-year outcomes from the REACH study. Gerontologist. 2003;43(4):547-555.

10. Census and Statistics Department Hong Kong Special Administration Region (HKSAR). Usage of Personal Computers and Internet Services by Hong Kong Residents, 2000 to 2012 [Hong Kong Monthly Digest of Statistics feature article]. Hong Kong SAR: Census and Statistics Department; 2013. Available from: http://www.censtatd.gov.hk/hkstat/ sub/sp120.jsp?productCode=FA100109. Accessed February 2, 2014.

11. Andersson G, Cuijpers P. Internet-based and other computerized psychological treatments for adult depression: a meta-analysis. Cogn Behav Ther. 2009;38(4):196-205.

12. Cuijpers P, Marks IM, van Straten A, Cavanagh K, Gega L, Andersson G. Computer-aided psychotherapy for anxiety disorders: a meta-analytic review. Cogn Behav Ther. 2009;38(2):66-82.

13. Spek V, Cuijpers P, Nyklícek I, Riper H, Keyzer J, Pop V. Internet-based cognitive behaviour therapy for symptoms of depression and anxiety: a meta-analysis. Psychol Med. 2007;37(3):319-328.

14. Blom MM, Bosmans JE, Cuijpers P, Zarit SH, Pot AM. Effectiveness and cost-effectiveness of an internet intervention for family caregivers of people with dementia: design of a randomized controlled trial. $B M C$ Psychiatry. 2013;13:17.

15. Nichols LO, Chang C, Lummus A, et al; Resources for Enhancing Alzheimer's Caregivers Health II Investigators. The cost-effectiveness of a behavior intervention with caregivers of patients with Alzheimer's disease. J Am Geriatr Soc. 2008;56(3):413-420. 
16. Sörensen S, Duberstein P, Gill D, Pinquart M. Dementia care: mental health effects, intervention strategies, and clinical implications. Lancet Neurol. 2006;5(11):961-973.

17. Sörensen S, Pinquart M, Duberstein P. How effective are interventions with caregivers? An updated meta-analysis. Gerontologist. 2002;42(3): 356-372.

18. Au A, Li S, Lee K, et al. The Coping with Caregiving Group Program for Chinese caregivers of patients with Alzheimer's disease in Hong Kong. Patient Educ Couns. 2010;78(2):256-260.

19. Katona C, Livingston G. Depression and Anxiety in Dementia Caregivers. Depressive Disorders, Third Edition. New York, NY: John Wiley \& Sons, Ltd; 2009.

20. Liu W, Wang PC, Gray H, et al. Client satisfaction with a stress reduction program for Chinese dementia caregivers. Hallym Int J Aging HIJA. 2008;10(2):91-110.

21. Beck JS, Beck AT. Cognitive Behavior Therapy. Basics and Beyond. 2nd ed. New York, NY: The Guilford Press; 2011.

22. Kaufer DI, Cummings JL, Ketchel P, et al. Validation of the NPI-Q, a brief clinical form of the Neuropsychiatric Inventory. JNeuropsychiatry Clin Neurosci. 2000;12(2):233-239.

23. Leung VP, Lam LC, Chiu HF, Cummings JL, Chen QL. Validation study of the Chinese version of the neuropsychiatric inventory (CNPI). Int J Geriatr Psychiatry. 2001;16(8):789-793.

24. Au A, Lai MK, Lau KM, et al. Social support and well-being in dementia family caregivers: the mediating role of self-efficacy. Aging Ment Health. 2009;13(5):761-768.

25. Steffen AM, McKibbin C, Zeiss AM, Gallagher-Thompson D, Bandura A. The revised scale for caregiving self-efficacy: reliability and validity studies. J Gerontol B Psychol Sci Soc Sci. 2002;57(1):P74-P86.
26. Bass DM, McClendon MJ, Brennan PF, McCarthy C. The buffering effect of a computer support network on caregiver strain. JAging Health. 1998;10(1):20-43.

27. Marziali E, Donahue P. Caring for others: Internet video-conferencing group intervention for family caregivers of older adults with neurodegenerative disease. Gerontologist. 2006;46(3):398-403.

28. Akkerman RL, Ostwald SK. Reducing anxiety in Alzheimer's disease family caregivers: the effectiveness of a nine-week cognitive-behavioral intervention. Am J Alzheimers Dis Other Demen. 2004;19(2): 117-123.

29. Gallagher-Thompson D, Coon DW. Evidence-based psychological treatments for distress in family caregivers of older adults. Psychol Aging. 2007;22(1):37-51.

30. Hersch EC, Falzgraf S. Management of the behavioral and psychological symptoms of dementia. Clin Interv Aging. 2007;2(4):611-621.

31. Glueckauf RL, Ketterson TU, Loomis JS, Dages P. Online support and education for dementia caregivers: overview, utilization, and initial program evaluation. Telemed J E Health. 2004;10(2):223-232.

32. Bourgeois MS, Burgio LD, Schulz R, Beach S, Palmer B. Modifying repetitive verbalizations of community-dwelling patients with AD. Gerontologist. 1997;37(1):30-39.

33. Andrén S, Elmståhl S. Family caregivers' subjective experiences of satisfaction in dementia care: aspects of burden, subjective health and sense of coherence. Scand J Caring Sci. 2005;19(2):157-168.
Clinical Interventions in Aging

\section{Publish your work in this journal}

Clinical Interventions in Aging is an international, peer-reviewed journal focusing on evidence-based reports on the value or lack thereof of treatments intended to prevent or delay the onset of maladaptive correlates of aging in human beings. This journal is indexed on PubMed Central, MedLine, the American Chemical Society's 'Chemical Abstracts Ser-

\section{Dovepress}

vice' (CAS), Scopus and the Elsevier Bibliographic databases. The manuscript management system is completely online and includes a very quick and fair peer-review system, which is all easy to use. Visit http://www.dovepress.com/testimonials.php to read real quotes from published authors. 